\title{
Muga silkworm, Antheraea assamensis (Lepidoptera: Saturniidae) - an overview of distribution, biology and breeding
}

\author{
Amalendu TIKADER, KunJuPILLAI VIJAYAN and BeERA SARATCHANDRA
}

Research Coordination Section, Central Silk Board, Bangalore-560 068, Karnataka, India; e-mail: atikader_csgrc@yahoo.co.in

Key words. Lepidoptera, Saturniidae, muga silkworm, Antheraea assamensis, rearing, improvement, disease, grainage

\begin{abstract}
Muga silkworm (Antheraea assamensis Helfer) is endemic to Assam and adjoining areas in North-Eastern India, and naturally produces golden silk. From time immemorial, many ethnic and tribal groups have produced muga silk. Muga silkworms are mostly wild unlike the mulberry silkworm, which is completely domesticated. The muga silkworm is a single species with little genetic variation among populations, survives harsh climatic conditions and is subject to various diseases, pests and predators. Due to the high incidence of disease and natural enemies, and variations in climatic conditions, the production of muga silk has recently declined dramatically. In order to improve the productivity of this silkworm it is important to have a better knowledge of both its host plants and biology. Lack of knowledge of its genetics and host plants is a major bottleneck. This paper reviews various aspects of muga silkworm culture, including the availability of different populations, and methods used to select for improvement in survival, cocoon yield, disease resistance, conservation and egg production.
\end{abstract}

\section{INTRODUCTION}

Insects that are commercially used to produce silk are the mulberry silk moth (Bombyx mori) and non-mulberry silk moths (Antheraea spp. and Samia spp.). Nearly 80\% of the silk produced in India comes from B. mori. Although the non-mulberry silkworms are mostly wild or semi-domesticated, they provide an important source of employment and subsistence for the native population (tribal) in the forest regions of India, especially the NorthEastern region. Antheraea is one of the largest genera in the family Saturniidae most species of which produce valuable silk, but have not yet been domesticated for commercial exploitation. Most of the species of Antheraea are polyphagous and survive well on several species of plants. The life cycles, morphology, physiology, biochemistry and genetics of these silk moths are very different. These insects belong to the order Lepidoptera and two families, Bombycidae and Saturniidae, which differ markedly in structure and colour. All the Saturniidae, but not all the Bombycidae, spin silk. According to Nässig et al. (1996), the 1200-1500 species in the family Saturniidae occur throughout the world. Arora \& Gupta (1979) report that there are as many as 40 species of silk moths in India, while Jolly et al. (1975) report about 80 species in Asia and Africa that are used to produce silk commercially. These silk moths can be either univoltine or multivoltine depending on the geo-climatic conditions (Reiger et al., 2008).

The North-Eastern states of India, Sikkim, Assam, Nagaland, Tripura, Arunachal Pradesh, Meghalaya, Mizoram and Manipur, are the main centers of wild silk culture (Fig. 1), using silk collected from muga (A. assamensis Helfer), eri ( $S$. ricini Donovan), oak tasar (A. proylei Jolly), mulberry (B. mori L.) and tasar moths (A. mylitta Drury). Singh \& Chakravorty (2006) record 24 species of the family Saturniidae in the Northeastern states. These wild silkworms feed on different host plants and migrate from one area to another and breed continuously throughout the year. Although a few of the above mentioned wild silkworms are recorded in surveys and by expeditions (Thangavelu \& Borah, 1986; Thangavelu et al., 1987, 1988; Kakati \& Chutia, 2009), it is necessary to carry out systematic documentation of these silk moths and their host plant preferences in order to formulate a comprehensive strategy for the improvement, conservation and sustainable utilization of these seri-genetic resources (Thangavelu, 1991; Tikader, 2001a, b, 2011, 2012). One of these silkworms needs special mention, it is the muga silkworm (A. assamensis), which produces golden silk and is endemic to Northeast India (Fig. 2). The muga silkworm has been exploited commercially for several decades but there is little information on its distribution, genetic diversity, host plant preferences etc. In this article, we compile and construct a comprehensive overview of the current status of muga silkworm culture in India and identify the major areas in need of more research.

\section{DISTRIBUTION OF MUGA SILKWORM}

Muga silkworm, A. assamensis, occurs in the Brahmputra valley in Assam, East, West and South Garo hills of Meghalaya, Mokokchung, Tuensung, Kohima and Wokha districts of Nagaland, Lohit and Dibang valleys, Chanlang and Papumpare districts of Arunachal Pradesh, Tamenglong district of Manipur and Coochbehar district of West Bengal (Fig. 1; Singh \& Mishra, 2003). It also occurs in Northern Myanmar and the Kumaon and Kangra valleys in the western Himalayan hills, Sikkim, Himachal Pradesh, Uttar Pradesh, Gujarat, Pondicherry, Bangladesh, Indonesia and Sri Lanka (Das et al., 2000). 


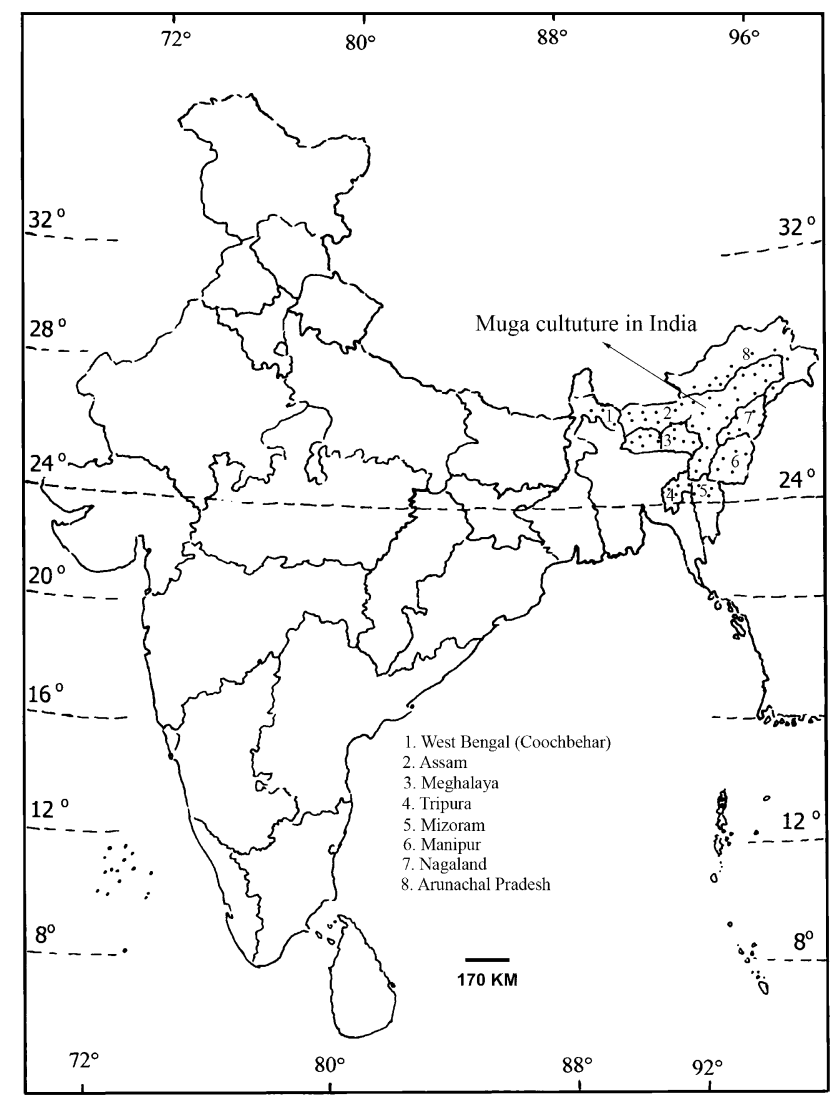

Fig. 1. Distribution of muga silkworm (A. assamensis) in India.

\section{SURVEYS AND THE COLLECTION OF BIOTYPES OF MUGA SILKWORM}

Although muga silkworm has not been successfully domesticated, attempts have recently been made to maintain it under semi-domesticated conditions and improve its economic traits (Thangavelu \& Sahu, 1983). The main reason for this is the marked inbreeding and their hibernating over winter. In particular different biotypes have been collected from various locations and maintained in culture. Some muga biotypes, like Halflong green, yellow mutant, Kokrapohia green and wild hibernating type, were collected from different areas and kept in off-site conditions and hybridized in order to determine whether their offspring show hybrid vigour. The biotypes were collected from Bhaktapara in lower Assam and Senchoa, Kamarbandha and Titabar in upper Assam, and wild muga silkworms, which diapause during winter, from a few areas in northeastern India. Chaudhury (1981) reports three biotypes of muga silkworm namely Sarubhagia, Barbhagia and Bor or Lebang. Different colour forms were also collected from farmer's fields. A survey was conducted in the foothills of Arunachal Pradesh, Assam, Meghalaya and Nagaland and the muga silkworms collected grouped into five biotypes (Type-W1: 24, Type-W2: 16, Type-W3: 12, Type-W4: 10 and Type-W5: 81). Other Antheraea species were also collected during this survey from northeastern and central India $(A$. assamensis, A. mylitta, A. frithii, A. pernyi and A. roylei). Recently during surveys in different districts of Assam (Golaghat, Jorhat, Sibsagar, Lakhimpur, North Cachar Hills, Kamrup, Goalpara, Nalbari, Bongaigaon and Kokrajhar, Karbianglong), Meghalaya (East, West and South Garo hills, East Khasi and West Khasi hills), Manipur (East and West Imphal, Churchandpur, Tamenglong and Chandal), Mizoram, Nagaland (Wokha, Mokokchung, Zunhebotto, Tuensung, Kohima), Arunchal Pradesh (Changlang, Lohit, Debang Valley, Papumpari) valuable wild silkworm biotypes were collected and are being maintained at Regional Muga Research Station (RMRS, Boko) and CMER\&TI, Lahdoigarh, Jorhat, Assam.

\section{CHARACTERIZATION AND EVALUATION OF MUGA SILKWORM}

The muga silkworm has been characterized in different ways. Arora \& Gupta (1979) used wing expansion while Chaudhury (1981) used features of cocoons, moths, eggs and larval traits. The haploid number of chromosomes of this species is 15 (Sengupta et al., 1975). Sahu (2005) cites a set of descriptors for the systematic characterization of muga silkworm (Table 1). In order to conserve the genetic diversity available in different populations, efforts are being made to develop a germplasm at Central Muga and Eri Research and Training Institute, Lahadoigarh. Recent findings indicate that there is significant genetic erosion occurring in wild populations and therefore there

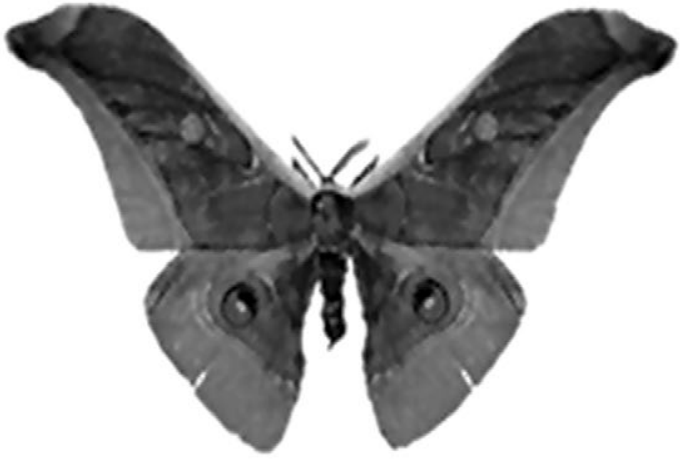

Male

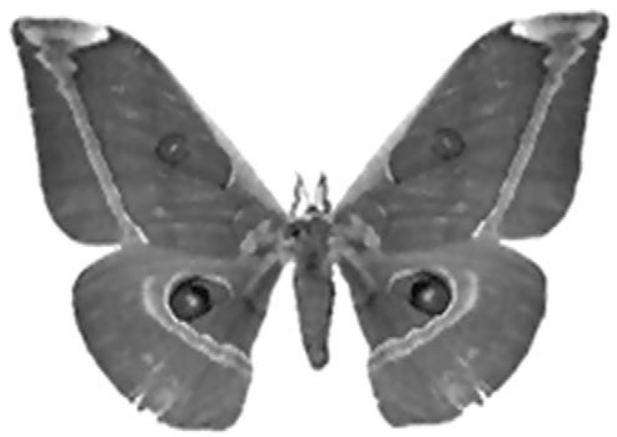

Female

Fig. 2. Male and female moths of muga silkworm (A. assamensis). 
TABLE 1. Morphometric characters of muga silkworm (A. assamensis).

\begin{tabular}{cccc}
\hline S1 & Characters & Wild stocks & Cultivated (semi-domesticated) \\
\hline 1 & Voltinism & Bivoltine / Multivoltine & Mutivoltine \\
2 & Number of moults & $4 / 3$ & 4 \\
3 & Food plant & Soalu / Dighloti & Som / Soalu \\
4 & Incubation period (days) & $8-12$ & $8-10$ \\
4 & Body colour & Black with yellow streak, Green & Black with yellow streak, Green \\
5 & Head colour & Light black & Brown \\
6 & Egg size (L $\times$ B) mm & $2.5-3.0 \times 2.0-2.5$ & $2.1-2.8 \times 2.0-2.4$ \\
7 & Egg weight (mg) & $8.36-9.33$ & $5.83-9.83$ \\
8 & Larval duration (days) & $22-50$ & $22-45$ \\
9 & Mature worm weight (g) & $9.0-14.0$ & $8.5-13.5$ \\
10 & Cocoon colour & Light golden & Light golden \\
11 & Cocoon shape & Elliptical & Elliptical \\
12 & Cocoon weight (g) & $4.5-8.55$ & $2.90-7.70$ \\
13 & Shell weight (g) & $0.60-0.96$ & $0.18-0.65$ \\
14 & Filament length (m) & $410-506$ & $126-398$ \\
15 & Filament fineness (denier) & $4-6$ & $4-6$ \\
16 & Percentage of silk reelable & $40-46$ & $37-63$ \\
17 & Silk recovery (\%) & $42-55$ & $40-42$ \\
18 & Fecundity (number of eggs) & 235 & 173 \\
\hline
\end{tabular}

Source: Sahu (2005); Tikader (2012).

is an important need to conserve germplasm. However, due to its monophyletic nature and lack of information on the genetic structure of the different populations of muga silkworm, there has been little progress. Nonetheless, eight biotypes collected from Assam, Meghalaya, Manipur and Nagaland are currently in culture and are being reared to assess their performance. The economic parameters of cocoons recorded for these biotypes (Table 2) indicate that in terms of fecundity, cocoon shell weight and filament length Aa-TM, Aa-KA and Aa-SD are the best performers (Singh et al., 2012a).

\section{DIAPAUSE BEHAVIOUR OF MUGA SILKWORMS}

Occurrence of natural populations of insects is a spontaneous phenomenon (Varley et al., 1973). The existence of variants in natural populations indicates the presence of a heterozygous genetic structure (Thangavelu \& Bhagawati, 1984). Physiological and behavioural adaptation to different seasonal environments is an important character of most insects (Tauber \& Tauber, 1976; Kakati et al., 2005). Unlike the mulberry silkworm, B. mori L., which undergoes diapause in the egg stage (Saunders, 1976) species of Antheraea undergo diapause in the pupal stage, except $A$. yamami, which undergoes diapause in both the egg and pupal stages (Jolly et al., 1973; Ahsan et al., 1976; Choudhury, 1981; Kato \& Sakate, 1982; Sakate, 1982; Kuribayashi, 1984; Khanikor \& Dutta, 1997, 1998, 2000). The number of generations per year that the muga silkworm completes in situ and ex situ populations differs. The cultivated stock, which has been subjected to domestication is now multivoltine, whereas the wild population is univoltine (Choudhury, 1981; Thangavelu \& Bhagawati, 1984).

\section{MAINTENANCE OF STOCKS OF MUGA SILKWORM}

Unlike domesticated B. mori it is not easy to rear the muga silkworm in captivity. In the wild this silkworm is found on som (Persea bombycina), soalu (Litsea monopetala) and dighloti (Litsea salicifolia) trees. Of these trees, soalu is semi-deciduous and sheds most of its leaves during winter. Thus, in the field muga silkworm hibernate in winter when there is a shortage of fresh leaves. However, the muga silkworms that feed on som trees do not hibernate (Kakati, 1991, 1993). The behaviour of diapause and non-diapause stocks is shown in Table 3. From a commercial point of view, it is important to isolate diapausing stock during Jarua (Nov-Jan) and Chotua (Feb-March) when they are subject to high mortality due to fungal diseases and parasitization by uzi fly (Exorista bombycis) and wasps. Moreover there is no shortage of eggs during Jethua (April-May) as sufficient eggs are produced by the Kotia (Oct-Nov) commercial crop. The optimum conditions for rearing of muga silkworm are $20-31{ }^{\circ} \mathrm{C}$ temperature and 65 to $95 \%$ relative humidity.

\section{IMPROVEMENT OF MUGA SILKWORM BY BREEDING AND SELECTION}

The genetic diversity of muga silkworm in culture, in which there are more than two or three generations per year, rapidly decreases. The offspring of crosses between green and yellow coloured individuals from different regions showed a $30-40 \%$ increase in characters such as larval weight, cocoon weight, shell weight and filament length. The yellow mutant can easily be crossed with the green mutant (Green $\times$ Yellow and Yellow $\times$ Green). The hibernating stocks perform better when crossed with yel- 
TABLE 2. Performance of of different biotypes of muga silkworm (A. assamensis).

\begin{tabular}{|c|c|c|c|c|c|c|c|c|}
\hline \multirow[b]{2}{*}{ Biotypes } & \multirow{2}{*}{$\begin{array}{l}\text { Fecundity } \\
\text { (nos) }\end{array}$} & \multirow{2}{*}{$\begin{array}{c}\text { Hatching } \\
\%\end{array}$} & \multirow[b]{2}{*}{ ERR \% } & \multicolumn{2}{|c|}{ Female } & \multicolumn{2}{|c|}{ Male } & \multirow{2}{*}{$\begin{array}{l}\text { Single cocoon } \\
\text { filament length } \\
(\mathrm{m})\end{array}$} \\
\hline & & & & $\begin{array}{c}\text { Cocoon } \\
\text { weight }(\mathrm{g})\end{array}$ & $\begin{array}{l}\text { Shell weight } \\
\text { (g) }\end{array}$ & $\begin{array}{c}\text { Cocoon } \\
\text { weight }(\mathrm{g})\end{array}$ & $\begin{array}{l}\text { Shell weight } \\
\text { (g) }\end{array}$ & \\
\hline Aa-SD & 138 & 76.0 & 93.0 & 6.71 & 0.50 & 4.28 & 0.35 & 289 \\
\hline Aa-Blue & 140 & 75.0 & 91.0 & 6.30 & 0.54 & 4.13 & 0.35 & 302 \\
\hline Aa-MM & 172 & 80.0 & 81.0 & 6.80 & 0.48 & 4.70 & 0.49 & 388 \\
\hline Aa-GM & 135 & 77.8 & 82.0 & 6.28 & 0.52 & 4.50 & 0.46 & 350 \\
\hline Aa-TM & 168 & 83.3 & 77.0 & 6.54 & 0.75 & 5.05 & 0.52 & 411 \\
\hline Aa-IM & 165 & 70.0 & 85.0 & 6.54 & 0.47 & 4.39 & 0.47 & 328 \\
\hline Aa-KA & 145 & 74.5 & 83.0 & 7.22 & 0.72 & 4.86 & 0.47 & 393 \\
\hline Aa-SM & 170 & 70.0 & 79.0 & 6.99 & 0.57 & 4.39 & 0.45 & 343 \\
\hline $\mathrm{CD}$ at $5 \%$ & 2.75 & 1.96 & 5.45 & 0.008 & 0.12 & 0.007 & 0.048 & 35.7 \\
\hline $\mathrm{CD}$ at $1 \%$ & 4.03 & 2.87 & 9.36 & 0.011 & 0.03 & 0.01 & 0.013 & 52.3 \\
\hline
\end{tabular}

Source: Singh et al. (2012a).

low. In the intra population crosses, the reproductive vigour of the yellow mutant lines M3BP, M3PB, M3P, MK1 and MK2 gradually decreased and they died out as a result of poor larval survival and inbreeding depression, with only a few lines surviving for 6-8 generations. Thangavelu et al. (1987) collected muga silkworm genetic stocks and isolated the following five variants: yellow morph, one with yellow lateral lines, one in which the moths were black, the winter diapausing wild type and non-diapausing wild type. Siddiqui \& Das (2000) found that genetic variation, expressed in terms of the genotypic co-efficient of variation, was low and most of the traits varied little, and they concluded that there was a need to isolate pure lines and use these in a future breeding program. At the research stations RMRS and Boko the following wild stocks: RMRS-Aa-001, Aa-002, Aa-003 and Aa-004, have been crossed and strains with improved cocoon traits, such as cocoon weight, shell weight and fecundity, produced. Thus, it is possible to exploit hybrid vigour by crossing genetically different lines. Singh et al. (2012b) report that quantitative traits like cocoon weight and fecundity have a high PCV, GCV and heritability. The GCV was near to PCV for most of the economic cocoon traits indicating a highly significant effect of genotype on phenotypic expression, with the environment having very little effect. High heritability estimates indicate the presence of a large number of fixable factors and hence it may be possible to improve these characters by selection. Thus, by progeny testing and further selection it should be possible to improve the cocoon traits that are of economic importance.

Recent research on molecular markers has resulted in the generation of 87 microsatellite markers from 35,000 expressed sequence tags and a microsatellite-enriched sub-genomic library (Arunkumar et al., 2009). In the future these microsatellite markers are likely to be widely used in genetic studies of A. assama and other closely related species. In this context Neog et al. (2010) have assessed eleven populations, comprising four from cultivated and seven from wild stocks with different geographical origins, using 50 RAPD primers. This study revealed that the populations are highly polymorphic, which is associated with their being able to survive in the diverse climatic conditions prevailing in north-eastern India. Arunkumar et al. (2012) used EST-SSRs and genomic SSRs to analyze 97 individuals from natural population collected from six different geographical locations in the Meghalaya states. This study revealed that one of the populations was genetically very different from the other populations. These studies indicate it might be

TABLE 3. Effect of egg incubation on growth of different life stages of muga silkworm. Duration of the different life stages, fecundity and the percentage of eggs of muga silkworm that hatched when reared at different times of the year (2003-2004).

\begin{tabular}{lcccccc}
\hline & \multicolumn{5}{c}{ Crops } & \\
\cline { 2 - 7 } Parameters & $\begin{array}{c}\text { Bhodia } \\
\text { (August-September) }\end{array}$ & $\begin{array}{c}\text { Kotia (October- } \\
\text { November) }\end{array}$ & $\begin{array}{c}\text { Jarua (December- } \\
\text { January) }\end{array}$ & $\begin{array}{c}\text { Chatua } \\
\text { (March-April) }\end{array}$ & $\begin{array}{c}\text { Jethua } \\
\text { (May-June) }\end{array}$ & $\begin{array}{c}\text { Aherua } \\
\text { (June-July) }\end{array}$ \\
\hline Incubation (days) & 7 & 8 & 12 & 10 & 10 & 8 \\
Fecundity (no. of eggs) & 316 & 208 & 188 & 105 & 190 & 172 \\
Hatching (\%) & 85.0 & 77.0 & 83.0 & 85.0 & 78.0 & 70.0 \\
Larval duration (days) & 21 & 23 & 47 & 28 & 21 & 21 \\
Pupal duration (days) & 20 & 22 & 41 & 24 & 18 & 17 \\
Longevity of moths (days) & 8 & 9 & 11 & 10 & 10 & 9 \\
\hline
\end{tabular}

Source: Kakati et al. (2005) 


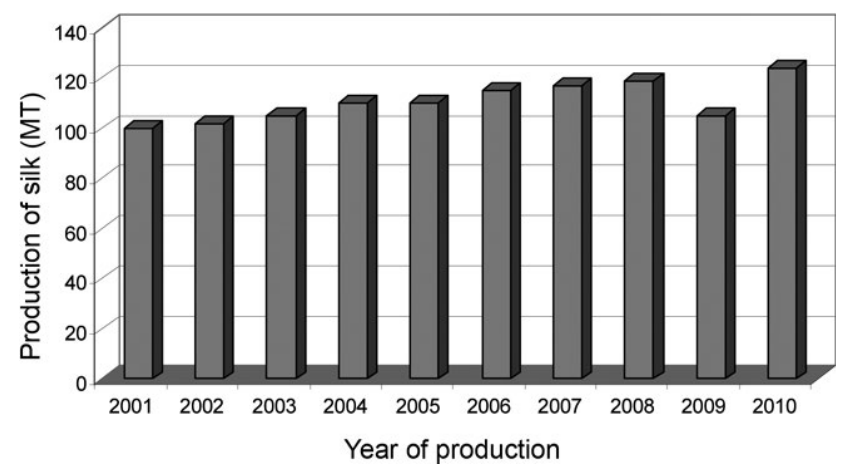

Fig. 3. Muga silk production showing a leveling off over the past 10 years.

possible to use inter population hybridization to improve the muga silkworm.

\section{BIOASSAY OF THE HOST PLANTS OF MUGA SILKWORM}

The muga silkworm is polyphagous and thrives on several species of plants, unlike the mulberry silkworm, which can survive only on mulberry. Muga silkworm feeds primarily on som (Persea bombycina), but will feed on soalu (Litsea monopetala), dighloti (L. salicifolia) and mejankari (L. citrata) if som is not available. Som occurs throughout Assam and is utilized there for the commercial rearing of muga silkworms (Neog et al., 2005). Based on the shape of its leaves, Choudhury (1981) identified three distinct morphotypes of som. The feeding rate of $A$. assamensis larvae depends on the morphology of the leaves of som (Hazarika et al., 1996) as this silkworm prefers the less pubescent small leaves that have short petioles. Although soalu occurs sporadically in the whole of North-East India, it is more abundant in Lower Assam. It is utilized for feeding muga silkworms for producing disease free eggs. Dighloti is a hardy shrub and occurs in the jungles of upper Assam. It is considered to be a secondary food plant of muga silkworm as larvae reared on it grow slowly and take a long time to complete their development and produce less silk.

The muga silkworm reared on different host plants differed greatly. The characteristics of the cocoons of muga silkworm reared on som are described by Ahmed et al. (1998). Tikader (2011) report the performance of the wild silkworm (Cricula trifenestrata) reared on different host plants. These studies reveal that the larvae of muga silkworm reared on hybrid plants grew faster and spent less time in each instar (Tikader \& Rajan, 2012) (Table 4). Though the wild silkworm sector of sericulture has recently become more important, much needs to be done to stop the current decline in the production of muga silk (Fig. 3; Tikader et al., 2011). In this context the leaves of tetraploid som plants provide a better food for rearing muga silk worm larvae, but this has not yet been exploited commercially at the farmer level (Gogoi et al., 2009). It is important to do further research on improving the quality of the host plant for muga silkworms as this will have a significant effect on silk quality and quantity.

\section{MUGA SILKWORM EGGS}

Muga culture is an age-old practice and the production of high quality eggs is a pre-requisite for the development of the sericulture industry. The scarcity of high quality eggs for commercial rearing is thought to be the main reason for the decline in muga silk production. In addition to the losses due to natural causes, diseases and natural enemies, there are the other factors responsible for the poor productivity. The majority $(80.0 \%)$ of the eggs received by the farmers have not been tested scientifically and are thus of poor quality. Muga silk industry is primarily in the hands of those who rear this silkworm to produce eggs and thus it is difficult to ascertain the exact production of eggs. The government has established farms, P4, P3 and P2, at strategic locations within the distribution of wild muga, which procure cocoons and maintain cultures that are used to provide seed cocoons for the people who rear them commercially (Borpuzari, 2010). The cocoons supplied by these government farms are microscopically examined to ensure that they are free of diseases and parasitoids (Thangavelu et al., 1988).

Storing of seed cocoons during favorable seasons is another method of improving the supply of eggs of muga silkworm. The muga cocoons are kept at a low temperature for different periods viz., 32, 42 and 52 days. The performance of the adults that emerged from the cocoons revealed that it is best keep them at $7.5^{\circ}$ or $10^{\circ} \mathrm{C}$ for 32 and 42 days, respectively. Studies on the effect of storage of muga seed cocoons on fecundity and hatching revealed that they can be stored for up to 62 days during winter and 42 days during autumn without any adverse effect on the quality and quantity of eggs.

\section{NATURAL ENEMIES OF MUGA SILKWORM}

Muga silkworm is subject to viral, bacterial, fungal and protozoan diseases that result in heavy crop losses (Table

TABLE 4. Performance of muga silkworm reared on different host plants.

\begin{tabular}{|c|c|c|c|c|c|c|}
\hline \multirow{2}{*}{ Host plant } & \multicolumn{2}{|c|}{ Single cocoon weight $(\mathrm{g})$} & \multicolumn{2}{|c|}{ Single shell weight $(\mathrm{g})$} & \multicolumn{2}{|c|}{ Silk ratio (\%) } \\
\hline & Male & Female & Male & Female & Male & Female \\
\hline Som & 3.64 & 5.36 & 0.293 & 0.360 & 8.049 & 6.716 \\
\hline Soalu & 4.02 & 6.15 & 0.300 & 0.416 & 7.462 & 6.764 \\
\hline Dighloti & 3.39 & 5.21 & 0.256 & 0.383 & 7.551 & 7.351 \\
\hline Hybrid & 3.75 & 5.41 & 0.293 & 0.380 & 7.813 & 7.024 \\
\hline Mean & $3.70 \pm 0.23$ & $5.53 \pm 0.36$ & $0.285 \pm 0.02$ & $0.384 \pm 0.02$ & $7.718 \pm 0.23$ & $6.963 \pm 0.25$ \\
\hline
\end{tabular}


TABLE 5. Major diseases and natural enemies of muga silkworm.

\begin{tabular}{|c|c|c|c|c|}
\hline $\mathrm{S} 1$ & 1 Disease & $\begin{array}{l}\text { Causal } \\
\text { organism }\end{array}$ & Symptoms & Crop loss $(\%)$ \\
\hline 1 & Pebrine & $\begin{array}{l}\text { Protozoa } \\
\text { (Nosema } \text { spp.) }\end{array}$ & Pebrine infected larvae develop black dots on the surface of their bodies. & $\begin{array}{l}40 \% \text { or even } \\
\text { total loss of crop }\end{array}$ \\
\hline 2 & Grasserie & Virus & $\begin{array}{l}\text { The haemolymph of infected larvae turns milky and contains numerous hex- } \\
\text { agonal crystals in suspension which can be seen when viewed under a micro- } \\
\text { scope. }\end{array}$ & $20-30 \%$ \\
\hline 3 & Flacherie & Bacteria, virus & $\begin{array}{l}\text { Common symptoms of this disease are lethargic larvae with swollen bodies, } \\
\text { which feed little and have drooping heads. }\end{array}$ & $20-30 \%$ \\
\hline 4 & Muscardine & Fungus & $\begin{array}{l}\text { The infected silkworms become harder, paler and completely inactive. A white } \\
\text { encrustation envelopes the body, which becomes laterally compressed, dry, hard } \\
\text { and brittle. }\end{array}$ & $25-35 \%$ \\
\hline 5 & $\begin{array}{l}\text { Uzi } \\
\text { infestation }\end{array}$ & $\begin{array}{l}\text { Uzi fly (Exor- } \\
\text { ista sorbillans) }\end{array}$ & $\begin{array}{l}\text { The uzi fly lay eggs on the surface of the body of the silkworm, after hatching } \\
\text { the maggot burrows into the body of the silkworm and feeds on its haemolymph } \\
\text { and other tissues. }\end{array}$ & $25-30 \%$ \\
\hline
\end{tabular}

5) of up to $40 \%$ for individual diseases (Veeranna, 1999). It is estimated that $20-30 \%$ of the loss is due to pebrine (microsporidian) disease, which sometimes kills an entire silkworm culture. This disease is transmitted from infected mother to offspring by transovarial transmission and is termed a primary infection. This infection results in most of the worms dying in the second or third instar. Cross-transmission from diseased to healthy individuals can also result in serious losses (Chakrabarti \& Manna, 2008). This is referred to as a secondary infection and results in worms spinning flimsy cocoons of inferior quality. The only way to minimize the severity of this disease is the use of preventive measures as it is hard to eradicate the pathogen completely. The usual method for doing this is to examine the eggs under a microscope and reject those that are infected. Diseased larvae should be removed and destroyed immediately. To reduce the level of contamination the houses where the silkworms are reared should be disinfected before and after the production of eggs.

Grasserie disease is caused by a virus and can cause heavy crop losses. It infects larvae mainly in summer and rarely in winter. Apart from climatic conditions, the quality of leaves is an important factor determining the incidence of this disease. The infected larvae die during spinning or after pupation and adults on emergence. Infected moths have a flaccid body and crumpled small wings. Use of preventive measures during rearing and disease free eggs may reduce the incidence of this disease. Washing the eggs with formaldehyde, sodium hydroxide, hydrochloric acid, and potassium permanganate solutions is one way of killing the virus.

Flacherie is another common disease of muga silkworm. It is caused by a virus followed by secondary infection with bacteria. Incidence of this disease is highest in summer and this is thought to be due to sudden fluctuations in temperature coupled with poor food quality (Aruga et al., 1963). Mature larvae are generally more susceptible to the disease and die before spinning. Common symptoms of this disease are a swollen body, lethargy, reduced feeding and a drooping head. The protection of larvae in their early stages from sun and rain, use of disease free eggs and procurement of cocoons from disease free zones may reduce the incidence of this disease. Several plant products and antibiotics are used to control the bacterial diseases of muga silkworm (Dutta et al., 2010).

Muscardine is a less prevalent disease caused by a fungus (Fusarium spp.). It infects larvae mainly in winter. Infected larvae are hard, pale and completely inactive. A white encrustation envelops the body, which becomes laterally compressed, dry, hard and brittle. If the disease occurs at late age, the larva spins a cocoon but the pupa develops a white encrustation. Proper disinfection of eggs with $2 \%$ formaldehyde solution reduces the incidence of this disease. "Lahdoi" a chemical formulation was developed recently to control muscardine disease in muga silkworm (Das \& Das, 2010).

The muga silkworm is attacked by a wide range of parasitoids and predators. During winter, the muga silkworm is prone to parasitisation by the uzi fly (Exorista bombycis), which can result in a crop loss of $80 \%$ (Singh et al., 1993). Biological control of this fly using the parasitoid, Nesolynx thymus (Hymenoptera: Eulophidae) can result in the death of up to $95 \%$ of the flies, which if used along with uzi traps and nets is an effective way of reducing the losses caused by this fly.

\section{CONCLUSION}

Thus, from the above, it can be concluded that although muga culture has been practiced in Assam and adjoining areas since time immemorial, unlike mulberry silkworm culture, it still faces a large number of challenges. The major constraints identified are (1) Lack of information on the genetics of the host plant, which hampers crop improvement. The genetic diversity of the morphotypes needs to be assessed using molecular markers and morpho-biochemical methods prior to selecting plants for breeding purposes. Appropriate agronomical practices have to be developed for obtaining high quality leaves for rearing the silkworms. Since, propagation of trees from seed results in the generation of a heterogeneous population, suitable methods for the vegetative propagation of high quality plants needs to be developed. (2) It is 
believed there is only a single race of muga silkworm, which is endemic to the Brahmaputra valley in Assam and the adjoining hills of India. Muga silkworm rearing and the reeling and weaving of muga silk by the people of Assam are not only traditional but also an important part of the economy in rural areas. Because of its unique natural golden colour, durability, and fine texture the demand for muga silk has been steadily increasing in recent years, which indicates its tremendous market potential. Efforts to improve this silkworm genetically have not met with much success as the different populations do not appear to differ very much from one another. Therefore, it is important to determine if there are any genetically divergent populations with important economic traits. To increase the quality and supply of cocoons and eggs it is important to identify the best conditions for storing cocoons and improve disease management.

Thus, muga culture could be more important in the economic development of the North-Eastern regions of India if the challenges it currently faces can be overcome. For this it is important to improve the host plant, silkworm and culturing conditions.

\section{REFERENCES}

Ahmed R.Z., Choudhury S.N. \& Bhattacharya P.R. 1998: Variation in cocoon characteristics of muga silkworm (Antheraea assama Westwood) reared in som (Persea bombycina Kost) collected from different places of Upper Assam, India. - Sericologia 38: 699-702.

Ahsan M.M., Jolly M.S., Banerjee N.D. \& Viswakarma S.R. 1976: Role of phytohormone in terminating pupal diapause of A. myllita D. - Ind. J. Sericult. 15: 21-26.

Arora G.S. \& Gupta I.J. 1979: Taxonomic studies of the some of the Indian non-mulberry silk moths (Lepidoptera: Saturniidae). - Mem. Zool. Surv. India 16: 1-63.

Aruga H., Fukuda H. \& Yoshitake N. 1963: Observations on a polyhedrosis virus within the nucleus of the silk gland cells of the silkworm, Bombyx mori L. - J. Sericult. Sci. Jpn. 32: 213-218.

Arunkumar K.P., Kifayathullah L. \& Nagaraju J. 2009: Microsatellite markers for the Indian golden silkmoth, Antherae assama (Saturniidae: Lepidoptera). - Mol. Ecol. Res. 9: 268-270.

Arunkumar K.P., Sahu A.K., Mohanty A.R., Awasthi A.K., Pradeep A.R., Raje Urs S. \& Nagaraju J. 2012: Genetic diversity and population structure of Indian golden silkmoth (Antheraea assama). - Plos One 7: e43716.

BorPUZARI P. 2010: Management of mass commercial muga seed production. - J. Assam Sci. Soc. 51: 157-163.

Chakrabarti S. \& Manna B. 2008: Studies on cross infection of microsporidian spores of mulberry, eri and tasar silkworm to muga silkworm (Antheraea assamensis Helfer) and a new approach for management to pebrine disease in muga silkworm in Assam and west Bengal, India. - Zool. Res. Human Welfare 47: 447-460.

Choudhury S.N. 1981: Muga Silk Industry. Directorate of Sericulture and Weaving, Govt. of Assam, Gauhati, Assam, 33 pp.

DAS R. \& DAS K. 2010: Muscardine in pre-seed cocoon muga crop and its management. - Indian Silk 1: 16-17.

Das P.K., SAHU A.K. \& Babulal 2000: Management of muga silkworm and host plant germplasm. In Proceedings of the
National Workshop on Management of Sericultural Germplasm for Posterity held on 26-27 July 2000 at Central Sericultural Germplasm Resources Centre, Hosur, India. pp. 133-139.

Dutta P., Neog K., Das K., Das R., Handique P.K. \& ChakraVORTY R. 2010: Evaluation of some botanicals, antibiotics, carbon source and carrier against of the bacterial disease of muga silkworm Antheraea assamensis. - Sericologia 50: $1-9$.

Gogoi S.N., Ghosh P.L. \& Chakravorty R. 2009: Evaluation of superior Som (Persea bombycina Kost.) genotypes for Muga silkworms (Antheraea assamensis, Helfer.) through bioassay and chemoassay studies. — Indian J. Forestry 32: 419-422.

Hazarika R., Hazarika L.K., Kataky A., Kataky J.C.S., HazaRIKA A.K. \& DeKA P.C. 1996: Association of morphological and biochemical characters of Machilus bombycina with the feeding behaviour of Antheraea assama. - Sericologia 36: 511-518.

Jolly M.S., Ahsan M.M. \& Agarwal A. 1973: Role of phytohormone in terminating pupal diapause of A. myllita. In: Proccedings of the $12^{\text {th }}$ International Silk Congress, Barcelona, p. 7.

Jolly M.S., Chowdhury S.N. \& Sen S.K. 1975: Non-mulberry sericulture in India. Central Silk Board, Bombay, $25 \mathrm{pp}$.

KAKATI L.N. \& Chutia B.C. 2009: Diversity and ecology of wild sericigenous insects in Nagaland, India. - Trop. Ecol. 50: $137-146$.

KAKATI P.K. 1991: Biology and bionomics of muga silkworm Antheraea assama $W w$. (Saturniidae: Lepidoptera) with special emphasis on the economic in North east India. Ph.D. Thesis. Dibrugarh University, Assam.

KAKATI P.K. 1993: Diapause strain of muga silkworm - an alternative to boost up muga industry. - Indian Silk 31: 22-25.

Kakati P.K., Handique P.K., Rana B. \& Chakravorty R. 2005: Isolation of winter diapause strain in muga silkworm Antheraea assamensis Helfer. In Proceedings: Strategies for Maintenance of Non-Mulberry Silkworm and Host Plant Germplasm Held at Central Muga Eri Research \& Training Institute, Lahdoigarh, Jorhat, Assam, India on March 10-11. pp. 217-224.

Kato Y. \& Sakate S. 1982: Pupal Summer Diapause in the Japanese Oak Silkworm A. yamamai. Research Information on Non-Mulberry Silkworm and Silk. The International Society for Non-Mulberry Silk, Japan.

KHANIKor D.P. \& DutTA S.K. 1997: Induction of pupal diapause in muga silkworm (Antheraea assama Westwood) (Lepidoptera: Saturniidae). - J. Assam Sci. Soc. 39: 40-44.

KHANIKOR D.P. \& DUTTA S.K. 1998: Effect of induced pupal diapause on rearing performance and cocoon parameters of muga silkworm (Antheraea assama Ww.) - J. Agric. Sci. Soc. 22: 140-143.

Khanikor D.P. \& DutTa S.K. 2000: Low temperature preservation of seed cocoons for delaying moth emergence in muga silkworm (Antheraea assama Westwood). Int. J. Wild Silkworm Silk 5: 216-220.

KURIBAYASH S. 1984: Non-mulberry silkworm rearing in Japan with special reference to Japanese oak silkworm A. yamami. In: Proceedings of the XVI. International Sericulture Congress (Non-mulberry Silk), 21-25 May 1984, Bangalore.

NÄssig W.A., Lempe R.E.J. \& Keger S. 1996: The Saturniidae of Sumatra (Lepidoptera). - Heterocera Sumatrana 10: 3-10.

Neog K., Gogor S.N. \& Chakravorty R. 2005: Present status and constraints of muga silkworm host plant germplasm conservation. In: Proceedings of the Workshop on Strategies for Maintenance of Non-Mulberry Silkworm and Host Plant Germplasm Held at Central Muga Eri Research \& Training 
Institute, Lahdoigarh, Jorhat, Assam, India on March 10-11. pp. 1-10.

Neog K., Singh H.R., UnNi B.G. \& Sahu A.K. 2010: Analysis of genetic diversity of muga silkworm (Antheraea assamensis, Helfer; Lepidoptera: Saturniidae) using RAPD-based molecular markers. - Afr. J. Biotech. 9: 1746-1752.

Reiger J.C., Grant M.C., Mitter C., Cook C.P., Peigler \& Rougerie R. 2008: Phylogenetic relationships of all wild moths (Lepidoptera: Saturniidae) inferred from four proteincoding nuclear genes. - Syst. Entomol. 10: 1-10.

SAHU A.K. 2005: Biodiversity of muga silkworm Antheraea assamensis Helfer. Present status and constraints of muga silkworm host plant germplasm conservation. In: Proceedings of the Workshop on Strategies for Maintenance of NonMulberry Silkworm and Host Plant Germplasm Held at Central Muga Eri Research \& Training Institute, Lahdoigarh, Jorhat, Assam, India on March 10-11. pp. 77-87.

SAKATE S. 1982: Embryological Experiments on A. yamami (Saturniidae: Lepidoptera). Research Information on NonMulberry Silkworm and Silk. The Int. Society for NonMulberry Silk, Japan.

SAunders D.S. 1976: Insect Clocks. Pergamon Press, Oxford, $280 \mathrm{pp}$.

Sengupta K., Singh K. \& Das S.K. 1975: Cytological Studies on Different Non-Mulberry Silkworm Species Found in Assam. Annual Report, Central Muga Eri Research Station, Titabor, Assam, pp. 25-39.

SidDIQUi A.A. \& DAS P.K. 2000: Genetic variation and correlation studies for technological traits in Antheraea asssama Ww. Endemic species of Northeast India. - Int. J. Wild Silkmoth Silk 5: 145-147.

SingH B.D. \& Mishra P.N. 2003: Culture of vanya silk vis-à-vis forestry with relevance to northwestern Himalayan ecosystem. In: Proceedings of the National Workshop on Vanya Silk Culture and Forestry Held on April 21-22, Dehardun. Bangalore, pp. 76-80.

Singh K.C. \& Chakravorty R. 2006: Present status and constraints of eri silkworm conservation in India. In: Proceedings of the Strategies for Non-Mulberry Germplasm Maintenance, Jorhat, Assam, India. pp. 88-96.

Singh P.K., Das P.K. \& Negi B.K. 1993: Studies on Seasonal Uzi Fly. Annual Report, Regional Muga Research Station, Boko, Assam, p. 7.

Singh N.I., Goswami D., Khan Z.M.S. \& Rajan R.K. 2012a: Evaluation of genetic resources of muga Antheraea assamensis Helfer and strategies to evolve superior breeds. In: Proceedings of National Seminar on Recent Trends in Research and Development in Muga Culture - Ideas to Action, Guwahati, 3-4 May 2012. pp. 38-43.
Singh N.I., Goswami D., Khan Z.M.S. \& RaJan R.K. 2012b: Genetic variability and heritability of a few quantitative characters in Antheraea assamensis Helfer an Indian silkworm. Ind. J. Genet. 72: 97-99.

TAuber M.J. \& TAuber C.A. 1976: Insect seasonability: diapause, maintenance, termination and post diapause development. - Annu. Rev. Entomol. 20: 81-107.

Thangavelu K. 1991: Wild sericigenous insects of India: A need for conservation. - Wild Silk Moths 91: 71-77.

Thangavelu K. \& Bhagowati A.K. 1984: Studies on natural population of $A$. assama. In: Proceedings of the XVI International Sericulture Congress (Non-Mulberry Silk), 21-25 May, 1984, Bangalore.

Thangavelu K. \& Borah A. 1986: Occurrence of Antheraea mylitta Drury (Lepidoptera: Saturniidae) in North eastern India - distributional significance. - Curr. Sci. 55: 940.

Thangavelu K. \& SahU A.K. 1983: Domestication of muga silkworm (Antheraea assama Ww.); a major breakthrough in muga culture. - Sericologia 23: 153-158.

Thangavelu K., Bhagowati A.K. \& Chakroborty A.K. 1987: Studies on some wild sericigenous insects of North-eastern India. - Sericologia 27: 91-98.

Thangavelu K., Chakroborty A.K., Bhagowati A.K. \& Isa M.D. 1988: Handbook of Muga Culture. Central Silk Board, Bangalore, pp. 75-88.

TIKADER A. 2001a: Occurrence of wild mulberry silkworm in Uttaranchal. - Indian Silk 40: 19-20.

TIKADER A. 2001b: Occurrence of wild mulberry silkworm. Textile Mag. 42: 35-36.

TIKADER A. 2011: Cricula trifenestrata Helfer feed on different host plants - A new report. - Geobios 38: 151-155.

TIKADER A. 2012: Feed performance of muga silkworm (Antheraea assamensis Helfer) on different host plants. Geobios 39: 104-108.

TIKADER A. \& RAJAN R.K. 2012: Utilization of muga host plants for cocoon crop improvement. In: Proceedings of National Seminar on Recent Trends in Research and Development in Muga Culture - Ideas to Action, Guwahati, India, 3-4 May 2012. pp. 68-71.

Tikader A., Gogol A.K. \& Pachuau L. 2011: Muga culture: the rich tradition of Assam. - Indian Silk 2: 18-20.

Varley G.C., Gradwell G.R. \& Hassell M.D. 1973: Insect Population Ecology - an Analytical Approach. Blackwell, Oxford, $211 \mathrm{pp}$.

VEERANNA G. 1999: Integrated silkworm disease management: China vs. India. — Indian Silk 7: 27-29.

Received August 20, 2012; revised and accepted October 14, 2012 